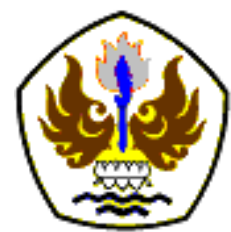

INFOMATEK

Volume 18 Nomor 2 Desember 2016

\title{
PEMBUATAN APLIKASI KELAYAKAN KREDIT MIKRO PADA PT. BPD JAWA BARAT DAN BANTEN,TBK.
}

\author{
Sandra Islama Putra ${ }^{\star}$, Rahmat Rusdiana \\ Program Studi Teknik Informatika \\ Fakultas Teknik - Universitas Pasundan
}

\begin{abstract}
Abstrak: PT. BDP Jawa Barat dan Banten,Tbk merupakan salah satu Perbankan yang bergerak dalam bisnis peminjaman uang dan suatu lembaga intermediasi dalam negara, salah satu produknya kredit mikro, berkenaan hal tersebut bank menutut para karyawan dapat memberikan pelayanan yang terbaik dan memuaskan kepada nasabahnya. Di era yang modern ini, teknologi bukan merupakan hal yang baru terutama di perusahaan. Hampir semua perusahaan menggunakan teknologi dalam menjalankan, mengembangkan dan mendukung oprasional segala jenis perusahaan bisnis. Dengan seiring perkembangan teknologi dan ilmu pengetahuan maka informasi memiliki peranan yang sangat penting untuk mendukung pengambilan sebuah keputusan, sehingga sistem manual mulai ditinggalkan, dan digantikan dengan sistem komputerisasi. Hal ini dikarenakan sistem manual seringkali membuat kinerja perusahaan terhambat dan kurang optimal. Oleh sebab itu dibuatkanlah aplikasi yang akan membantu bagian analis kredit mikro, untuk pengambilan keputusan kelayakan nasabah yang akan mengajukan kredit. Penganalisisan kelayakan ini didasarkan atas syarat yang telah ditentukan oleh PT. BDP Jawa Barat dan Banten, Tbk. Untuk menyelesaikannya masalah ini dibuatkanlah aplikasi kelayakan kredit mikro terhadap nasabah yang layak mengajukan dan meneria kredit yang didukung dengan bahasa pemrograman Visual Basic dan Sql Server sebagai media penyimpanan data.
\end{abstract}

Kata kunci: aplikasi, kredit mikro

\section{PENDAHULUAN}

\subsection{Latar Belakang}

Di era yang modern ini, teknologi bukan merupakan hal yang baru terutama di perusahaan. Hampir semua perusahaan menggunakan teknologi dalam menjalankan, mengembangkan dan mendukung oprasional segala jenis perusahaan bisnis. Salah satunya persaingan bisnis di bidang peminjaman uang. Perbankan salah satu lembaga intermediasidalam negara, berkenaan hal

\footnotetext{
*) sandra@unpas.ac.id
}

tersebut bank menutut para karyawan dapat memberikan pelayanan yang terbaik dan memuaskan kepada nasabah-nasabah.

PT. BDP Jawa Barat dan Banten merupakan salah satu perbankan yang memiliki berbagai jenis produk dan layanan, salah satunya adalah kredit mikro yang menjadi sasaran UMKM, nasabah yang mengajukan peminjaman harus diseleksi terlebih dahulu sesuai syarat yang telah ditentukan oleh pihak bank. Pada saat ini masih menggunakan 
sistem yang manual data pengajuan calon nasabah masih dicatat dalam sebuah buku, terutama dalam proses analisa yang lama. Adapun aplikasi yang sudah tersedia yaitu contigency yang terbuat dari microsft excel yang sangat sederhana sehingga tingkat percepatan atau otomatisasinya kurang semuanya memakan waktu yang sangat lama dan dalam penyimpanan berkas yang sudah di analisa masih secara manual tidak di simpan dalam sebuah database. Sehingga mengakibatkan pencarian data yang sudah adapun sangat sulit, berkenaan dengan hal tersebut PT. BDP Jawa Barat dan Banten membutuhkan suatu tool atau aplikasi yang dapat membantu meningkatkan kinerja analis dalam proses kredit mikro.

Oleh karena itu berdasarkan uraian diatas penulis tertarik untuk membantu pihak PT. BPD Jawa Barat dan Banten dibagian kredit mikro tersebut dalam mengolah data nasabahyang berhak menerima kredit dengan dibuatkan sebuah aplikasi yang menggunakan Visual Basic. Selain dikarenakan belum adanya aplikasi untuk mengambil keputusan kelayakan nasabah, visual basic merupakan aplikasi yang tidak semua orang dapat mengaksesnya lewat jaringan secara bebas, cukup user pada bagian analis kredit mikro yang berhak untuk mengaksesnya.
Hampir semua perusahaan menggunakan teknologi dalam menjalankan, mengembangkan dan mendukung oprasional segala jenis perusahaan bisnis. Dengan seiring perkembangan teknologi dan ilmu pengetahuan maka informasi memiliki peranan yang sangat penting untuk mendukung pengambilan sebuah keputusan, sehingga sistem manual mulai ditinggalkan, dan digantikan dengan sistem komputerisasi. Pada dasarnya sistem pendukung keputusan adalah sistem yang tidak bias dipisahkan dari teknologi komputer, hampir mustahil ketika sistem pendukung keputusan tidak melibatkan teknologi di dalam proses pengambilan keputusannya yaitu komputer. (Arfyanti [1]).

\section{METODOLOGI}

Metodologi yang digunakan dalam penelitian ini adalah sebagai berikut:

\section{Tahap pengupulan data}

Metode pengumpulan data yang digunakan dalam penelitian ini adalah sebagai berikut:

a. Studi Literatur

Pengumpulan data dengan cara mengumpulkan data atau informasi dengan mengambil dan membaca dari buku maupun situs-situs yang dijadikan rujukan atau referensi, penulis mendapatkan dari standar oprasional prosedur (SOP), Media internet (Pressman, wikipedia dll), baik buku atau bacaan yang terkait. 


\section{b. Observasi}

Teknik pengumpulan data dengan mengadakan penelitian dan peninjauan langsung terhadap permasalahan yang diambil, penulis menemukan penggunaan microsoft excel sebagai tool yang sedang digunakan.

\section{Tahap pembuatan perangkat lunak}

Teknis analsis data dalam pembuatan perangkat lunak menggunakan paradigma perangkat lunak secara waterfall, pada perinsinya pemodelan sistem waterfall pengembangannya dilakukan secara sistematis dan terarah dari tahap sistem, secara berurutan melalui tahap analisa, tahap design, coding, testing dan maintenance juga dapat kembali ketahap awal apabila semua tahapan pengembangan sistem telah dilalui. Pemodelan seperti ini juga dikenal sebagai model sekuensial linear.

\section{"Linear sequential model" (Pressman [2])} tahap-tahap pengembangan sistem dapat digambarkan dalam diagram yang meliputi beberapa proses diantaranya:

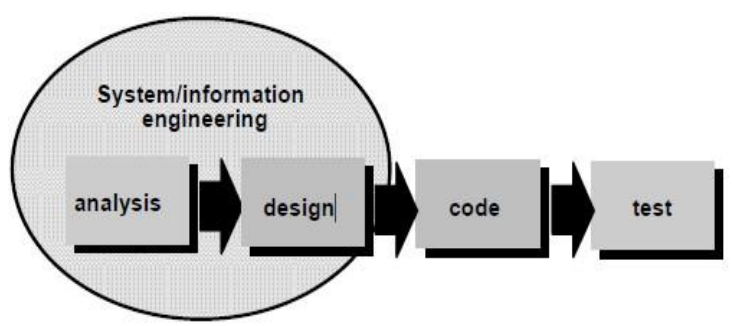

\section{Gambar 1}

Model waterfall (Pressman, 2002)

\section{a. System / Information Engineering}

System / Information Engineering membahas semua aspek produksi perangkat lunak mulai dari tahap awal yaitu analisa kebutuhan pengguna, menentukan spesifikasi dari kebutuhan pengguna, Desain, pengkodean, pengujian sampai pemeliharaan sistem setelah digunakan. Tetapi dalam kasus ini hanya menggunakan tahap analisa kebutuhan pengguna, desain, serta pengkodean tanpa melakukan pengujian dan pemeliharaan sistem.

Dari pengertian ini jelaslah bahwa System/ Information Engineering tidak hanya berhubungan dengan cara pembuatan program komputer. Pernyataan "semua aspek produksi" pada pengertian di atas, mempunyai arti semua hal yang berhubungan dengan proses produksi seperti manajemen proyek, penentuan personil, anggaran biaya, metode, jadwal, kualitas sampai dengan pelatihan pengguna merupakan bagian dari System/ Information Engineering.

b. Analisis

Merupakan tahap menganalisis hal-hal yang diperlukan dalam pelaksanaan pembuatan perangkat lunak. Analisis adalah sebuah teknik pemecahan masalah yang menguraikan sebuah sistem menjadi komponen- 
komponennya dengan tujuan mempelajari seberapa bagus komponen-komponen tersebut bekerja dan berinteraksi untuk meraih tujuan mereka.

Ada satu bagian penting yang biasanya dilakukan dalam tahapan analisis yaitu pemodelan proses bisnis. Analisis sistem berisikan requirement sebagai pendefinisian kebutuhan dalam pembuatan sistem.

Requirement dibedakan menjadi tiga jenis, yaitu (Hendrawan [3]):

- User Role Requirement (kebutuhan peran pengguna)

Pernyataan tentang layanan yang disediakan sistem dan tentang batasan-batasan operasionalnya. Pernyataan ini dapat dilengkapi dengan gambar/ diagram yang dapat dimengerti dengan mudah.

- System Requirement (kebutuhan sistem)

Sekumpulan layanan/ kemampuan sistem dan batasan-batasannya yang ditulis secara detil. System requirement document sering disebut functional specification (spesifikasi fungsional), harus menjelaskan dengan tepat dan detil. Ini bisa berlaku sebagai kontrak antara klien dan pembangun.
- Software design specification (spesifikasi rancangan $\mathrm{PL}$ )

Gambaran abstrak dari rancangan software yang menjadi dasar bagi perancangan dan implementasi yang lebih detil.

\section{c. Design}

Adalah tahap penerjemahan dari data yang dianalisis ke dalam bentuk yang mudah dimengerti oleh user atau Desain perangkat lunak yaitu tugas, tahapan atau aktivitas yang difokuskan pada spesifikasi detil dari solusi berbasis computer juga sebagai model yang memfokuskan pada seluruh proses di dalam sistem yang mentranformasikan data menjadi informasi. Model proses juga menunjukkan aliran data yang masuk dan keluar pada suatu proses.

Jika tahapan analisis sistem menekankan pada masalah bisnis (business rule), maka sebaliknya disain perangkat lunak fokus pada sisi teknis dan implementasi sebuah perangkat lunak. Output utama dari tahapan disain perangkat lunak adalah spesifikasi desain. Spesifikasi ini meliputi spesifikasi desain umum yang akan disampaikan kepada stakeholder sistem dan spesifikasi desain rinci yang akan digunakan pada tahap implementasi. Spesifikasi desain umum hanya berisi gambaran umum agar stakeholder 
sistem mengerti akan seperti apa perangkat lunak yang akan dibangun.

\section{d. Coding}

Istilah untuk baris perintah program yang di tulis programer dalam pembuatan sebuah program komputer, tahapan ini data atau pemecahan masalah yang telah dirancang penulis di terjemahkan atau dirumuskan ke dalam bahasa pemerograman komputer sehingga menjadi sebuah aplikasi yang diinginkan dan dapat dijalankan sesuai kebutuhan atau keinginan user.

\section{ANALISIS SISTEM}

\subsection{Analisis}

Pembuatan aplikasi kelayakan kredit mikro ini bertujuan untuk mempermudah proses dan menyimpannya kedalam sebuah database.

1. Langkah pertama, data calon debitur yang sudah lengkap beserta sitem informasi debitur (SID) dari pihak marketing (sales) diperiksa untuk mengetahui informasi calon debitur.

2. Memeriksa data calon debitur apakah sudah memenuhi syarat atau tidak dalam segi administratif, mengecek informasi debitur yang sudah di cek kepada Bank Indonesia (BI) oleh marketing apakah debitur memiliki pengalaman pemijaman di bank lain atau tidak,jika calon debitur memiliki pengalaman tadak lancar masalah pembayaran atau tidak memenuhi syarat di bank lain maka dibuat surat penolakan oleh admin, apabila calon debitur memiliki pengalaman pinjaman yang lancar maka dilakukan proses selanjutnya.

3. Analis melakukan survei On The Spot(OTS) ketempat debitur untuk memastikan kebenaran data yang telah diberikan dan memperoleh data atau informasi yang dibutuhkan dalam analisa tentang debitur.

4. Analis kredit mikro melakukan analisa kredit dengan beberapa tahapan contingency layak dan tidak layaknya calon debitur untuk diberikan kredit dalam peroses contingency.

\subsection{Requirement}

Aplikasi desktop yang akan dibangun perlu memiliki layanan-layanan sebagai System Requirement sebagai berikut:

\section{Functional Requirement}

a. Fungsi Pengelolaan data

1. Sistem dapat menangani tambah, edit, reset data informasi nasabah dan menyimpannya ke dalam database.

- Sistem dapat menangani pengelolaan terhadap data informasi pokok nasabah yang meliputi tambah, edit,riset. 
- Sistem dapat menangani pengelolaan terhadap data aspek non keuangan nasabah yang meliputi tambah, edit, riset.

- Sistem dapat menangani pengelolaan terhadap data aspek keuangan nasabah yang meliputi tambah, edit, riset.

- Sistem dapat menangani pengelolaan terhadap data aspek kebutuhan kredit nasabah yang meliputi tambah, edit, riset.

- Sistem dapat menangani pengelolaan terhadap data rekomendasi kredit yang meliputi tambah, edit, riset.

2. Non-functional Requirement

- Sistem tidak memerlukan jaringan bias digunakan kapan saja.

- Hak Akses

Untuk menghindari akses halaman terhadap pengguna yang tidak berhak.

\section{IMPLEMENTASI}

\subsection{Implementasi Sistem}

Pembuatan Aplikasi Kelayakan Kredit Mikro Pada PT. BPD Jawa Barat Dan Banten, digunakan sebagai tools dalam analisa kredit mikro. Aplikasi ini bertujuan untuk mempermudah proses kemudian data disimpan dalam suatu database agar tersimpan aman dan mempermudah pencarian data.

Aplikasi ini merupakan sebuah program sederhana menggunakan bahasa pemrograman visual basic.net dan database mysql, dengan tampilan berbasis Aplikasi dekstop. Dengan pembangunan aplikasi ini diharapkan proses bisa lebih cepat, tepat dan akurat.

\subsection{Kebutuhan Antarmuka Perangkat Lunak}

Kebutuhan Interface / antarmuka perangkat lunak menjelaskan mengenai segala sesuatu yang dibutuhkan berkenaan dengan pembuatan aplikasi kelayakan kredit mikro ini, mulai dari image atau gambar yang digunakan, warna yang digunakan, dan semua kakas, script tambahan yang digunakan untuk pembuatan aplikasi ini.

Image atau gambar yang digunakan pada aplikasi web ini cukup beragam, beberapa tipe image yang dipergunakan untuk melengkapi antara lain JPEG (Joint Photographic Experts Group), Semua image pada situs ini dibuat dengan menggunakan bantuan tools Adobe Photoshop CS4.

\subsection{Implementasi Antarmuka}


Berikut ini merupakan implementasi antarmuka aplikasi kelayakan kredit mikro.

\section{Tampilan Login}

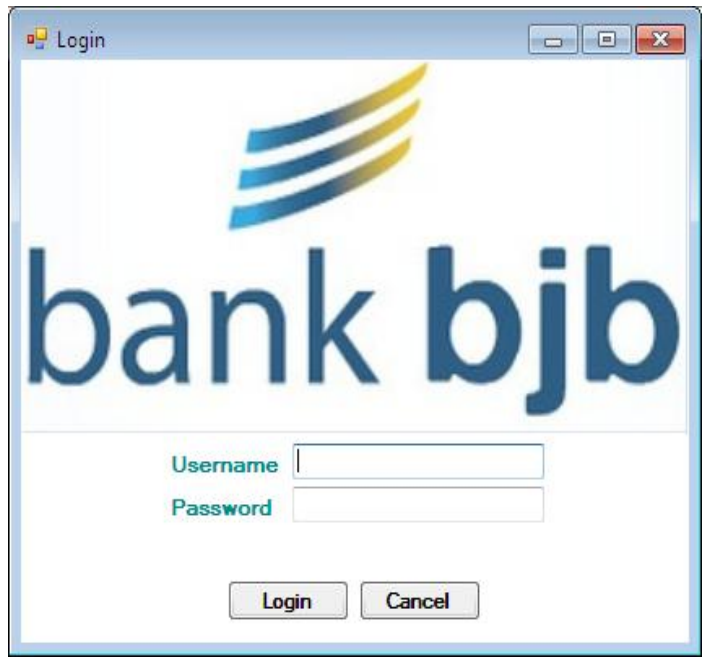

Gambar 2

Tampilan Login

2. Tampilan Menu Utama

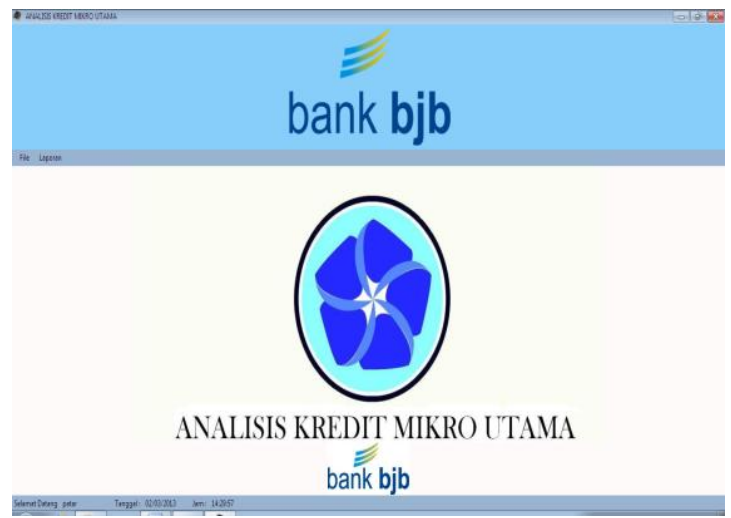

Gambar 3

Halaman Menu Utama

3. Tampilan Form Informasi Pokok

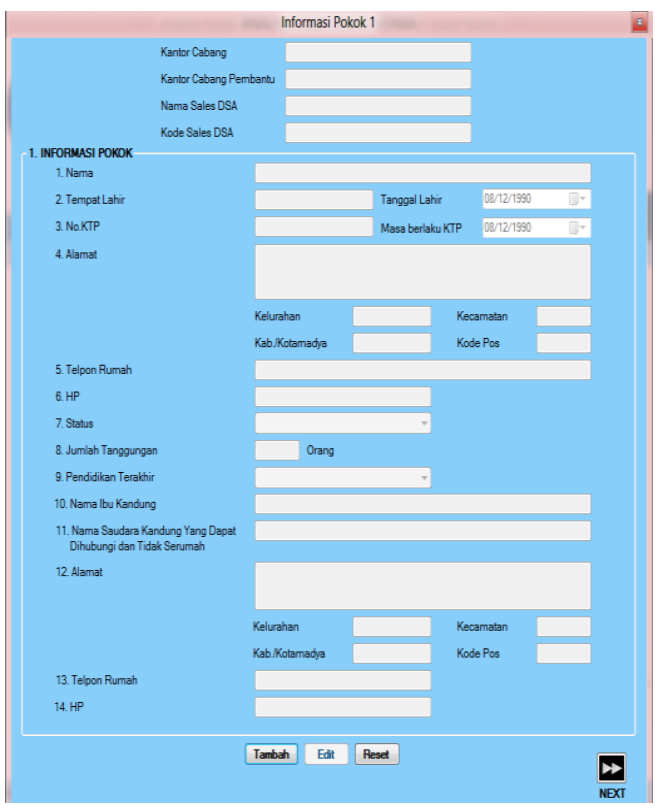

Gambar 4

Lanjutan Informasi pokok

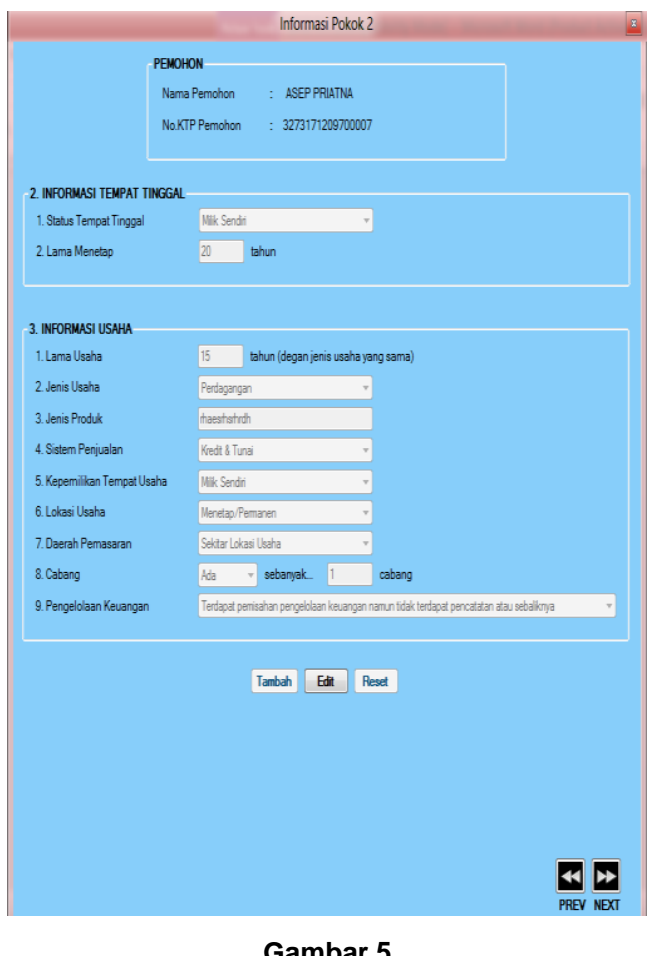

Lanjutan Informasi pokok 2 


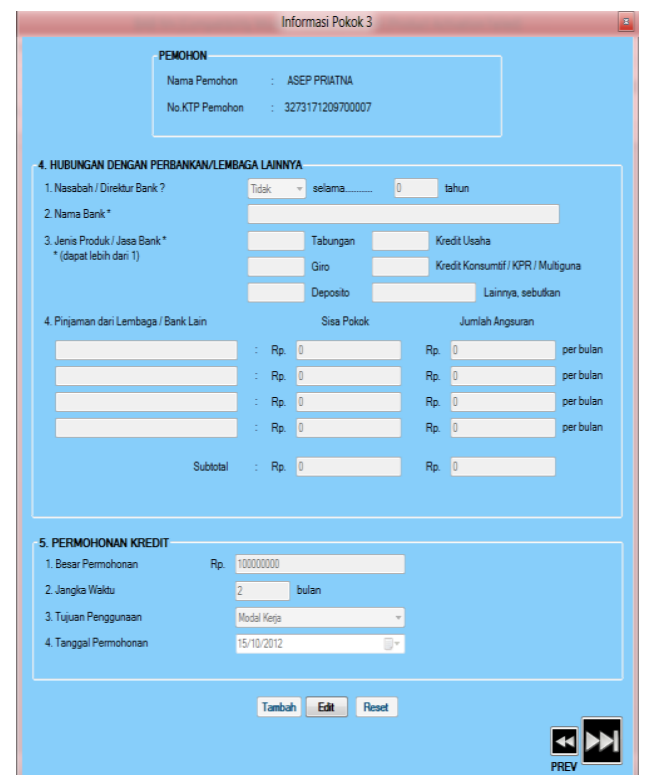

Gambar 6

Lanjutan Informasi Pokok 3

\section{Tampilan Menu Aspek Non Keuangan}

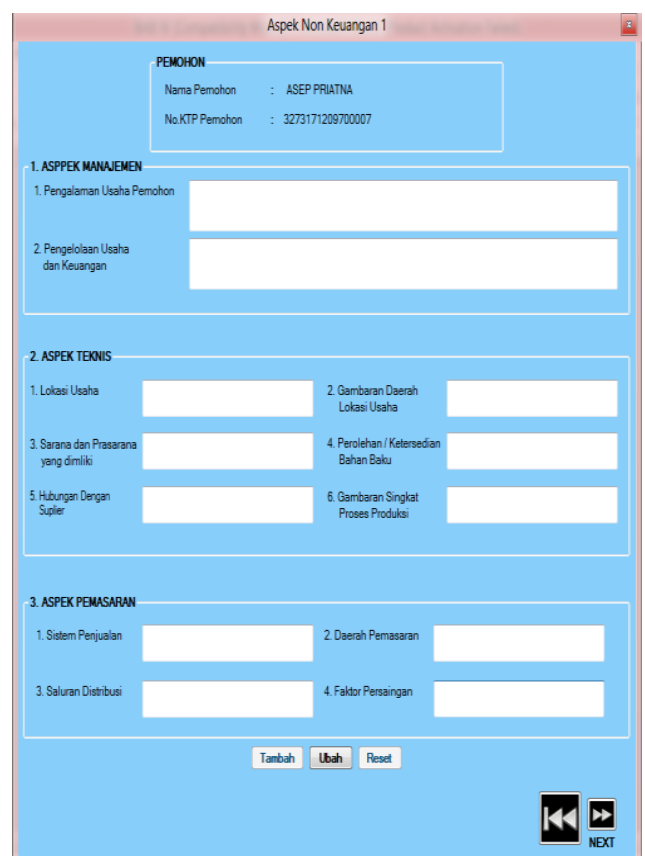

Gambar 7

Halaman Aspek Non Keuangan 1

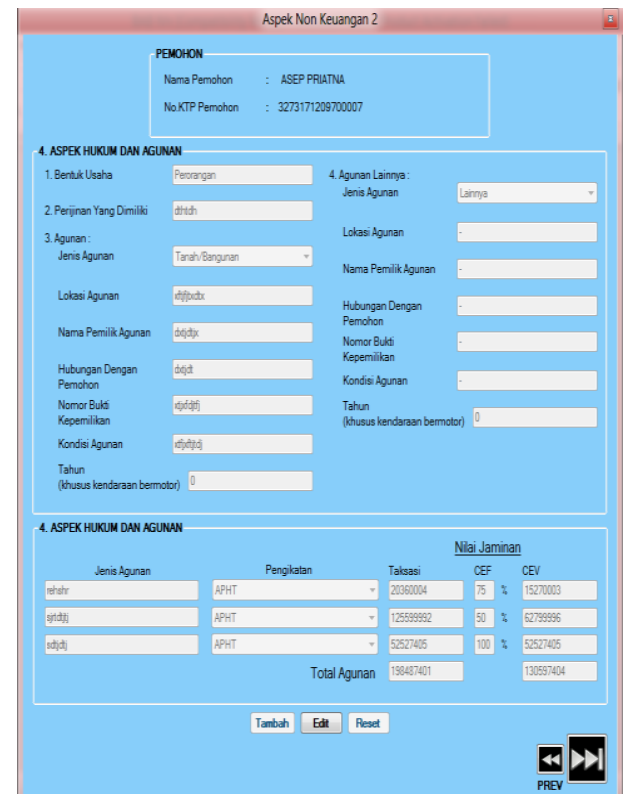

Gambar 8

Lanjutan Aspek Non Keuangan 2

\section{Tampilan Menu Aspek Keuangan}

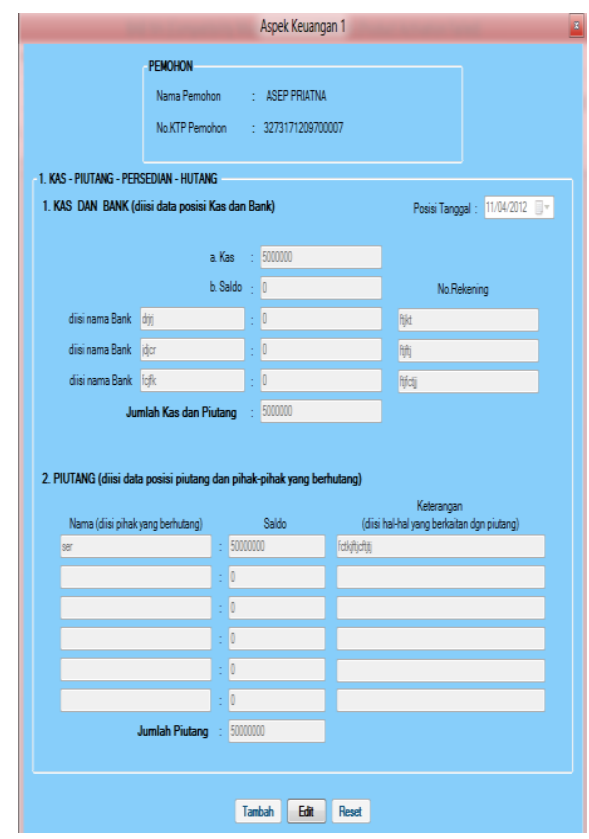

Gambar 9

Halaman Aspek Keuangan 1 
Pembuatan Aplikasi Kelayakan Kredit Mikro pada PT BPD Jawa Barat dan Banten, Tbk.

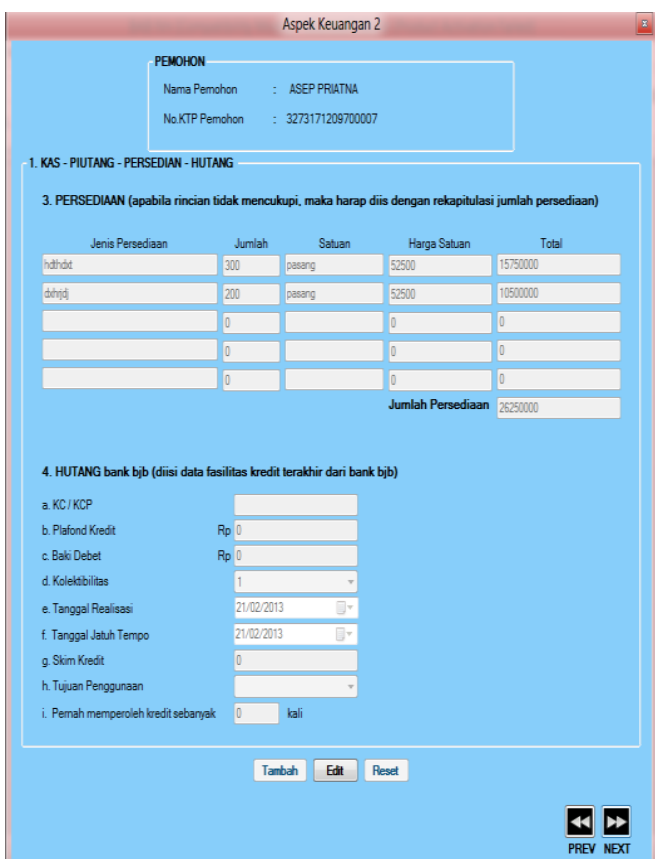

Gambar 10

Lanjutan Aspek Keuangan 2

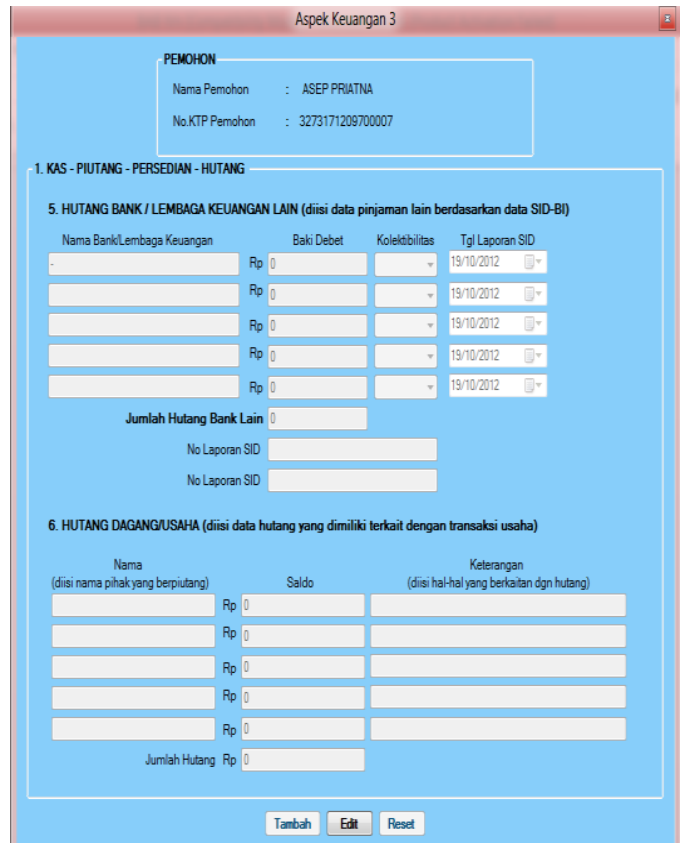

Gambar 11

Lanjutan Aspek Keuangan 4

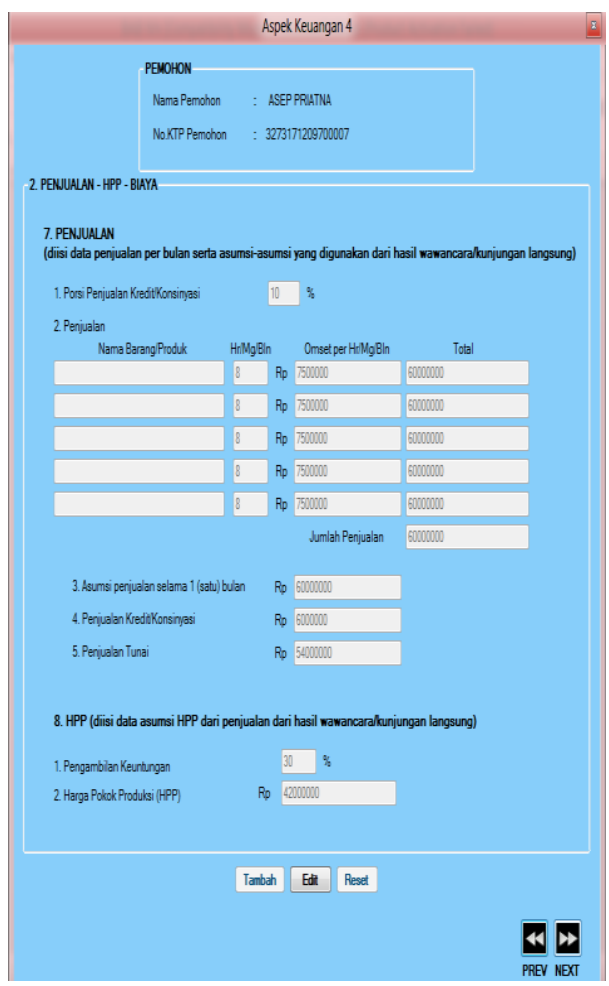

Gambar 12

Lanjutan Aspek Keuangan 5

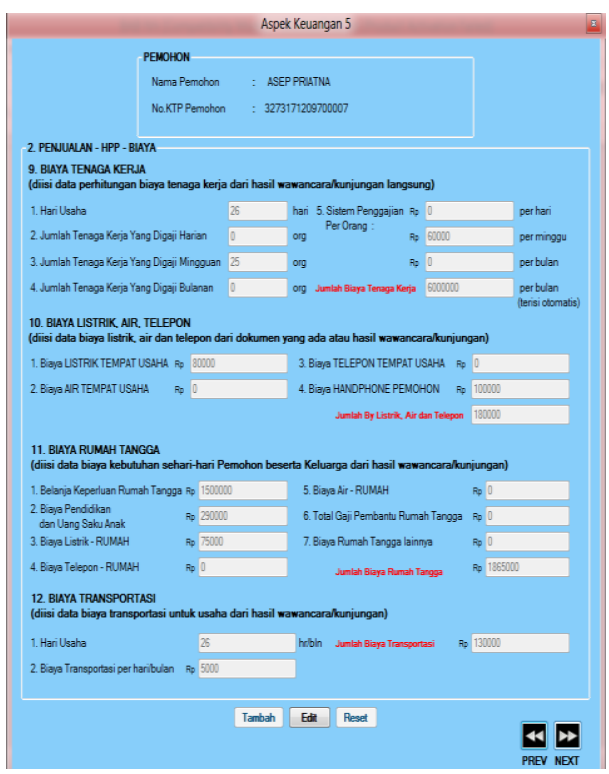

Gambar 13

Lanjutan Aspek Keuangan 6 


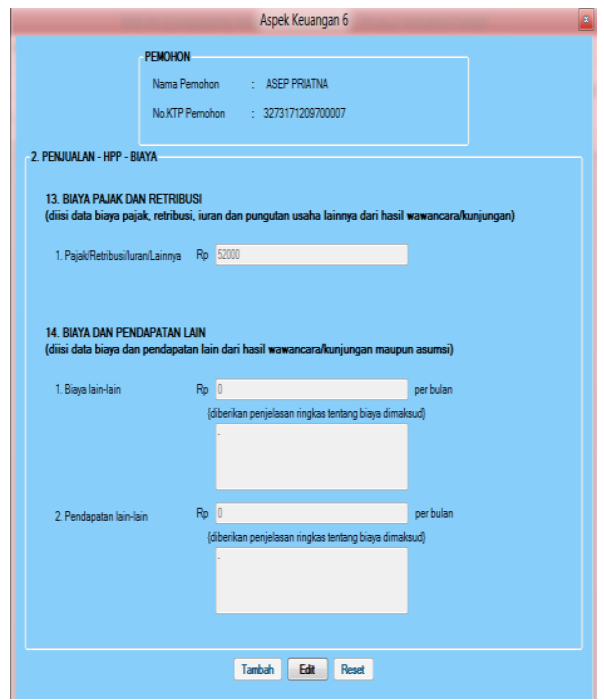

Gambar 14

Lanjutan Aspek Keuangan 7

\section{Tampilan Form Kebutuhan Kredit}

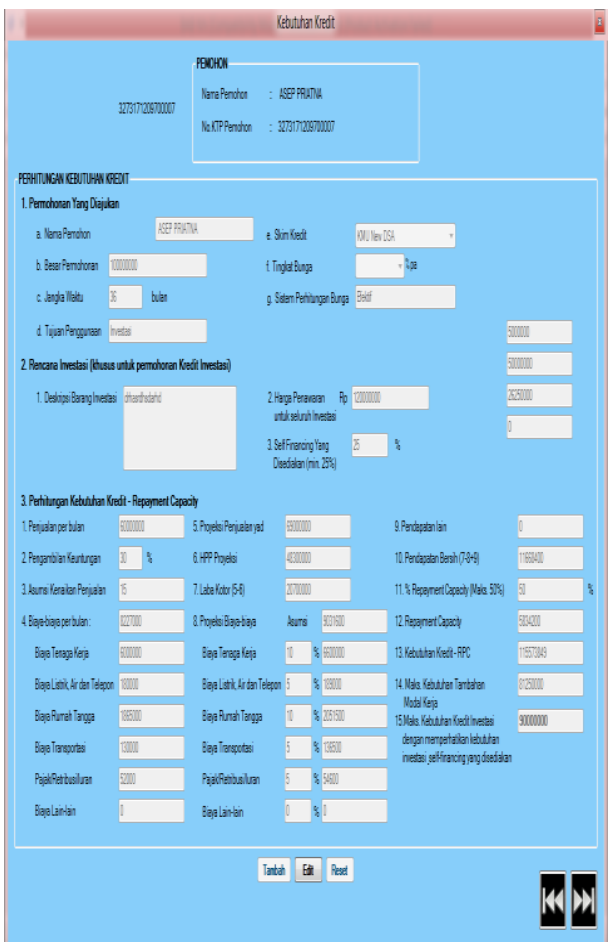

Gambar 15

Halaman Kebutuhan Kredit

\section{Tampilan Form Rekomendasi}

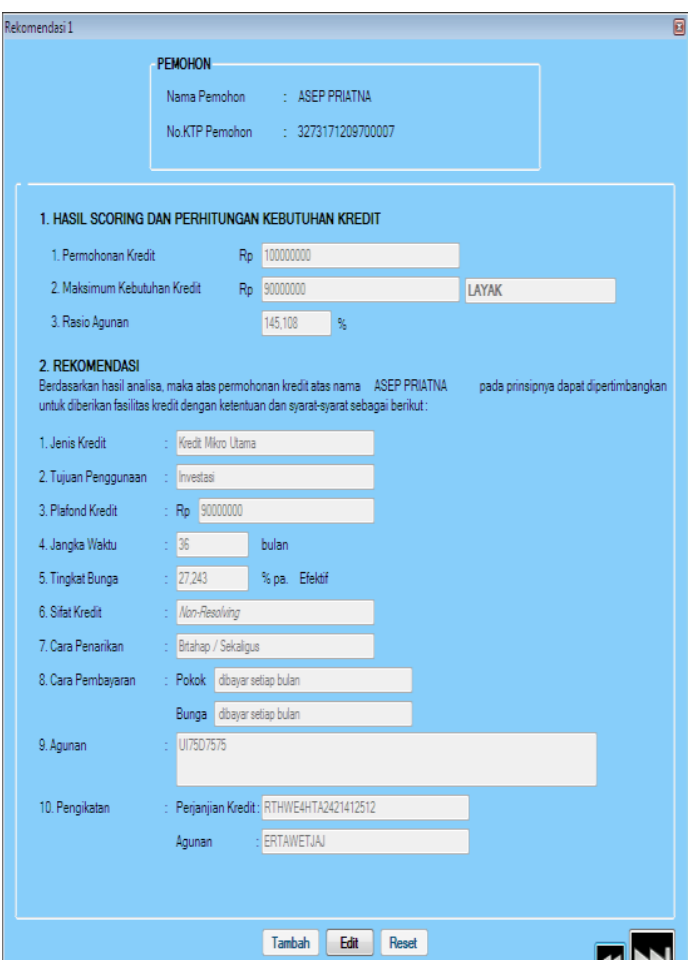

Gambar 16

Halaman Rekomendasi

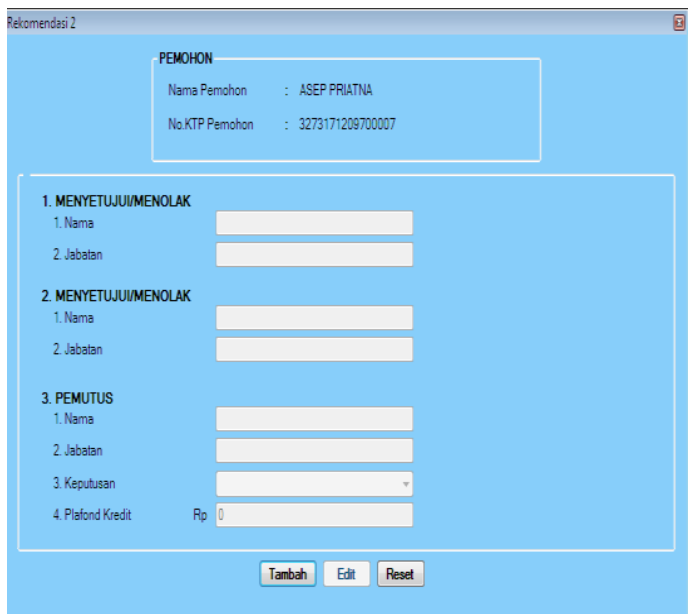

Gambar 17

Halaman Rekomendasi Lanjutan 


\subsection{Kebutuhan Perangkat Keras dan}

\section{Perangkat Lunak}

Adapun perangkat keras dan perangkat lunak yang penulis gunakan dalam pembuatan aplikasi kelayakan kredit mikro ini antara lain :

1. Perangkat keras (Hardware)

Tabel 1

Spesifikasi Perangkat keras

\begin{tabular}{|l|l|l|}
\hline No & \multicolumn{1}{|c|}{$\begin{array}{c}\text { Jenis } \\
\text { Hardware }\end{array}$} & Nama Hardware \\
\hline 1 & Processor & $\begin{array}{l}\text { Pentium Dual } \\
\text { Core i3 Ghz }\end{array}$ \\
\hline 2 & RAM & 1 GB DDR 3 \\
\hline 3 & Harddisk & Minimum 320Gb \\
\hline 4 & Kartu Grafis & SIS 64Mb \\
\hline 5 & Monitor & $\begin{array}{l}\text { CRT, LCD 17 } \\
\text { inch }\end{array}$ \\
\hline 6 & Printer & $\begin{array}{l}\text { Epson Stylus } \\
\text { C45 }\end{array}$ \\
\hline
\end{tabular}

2. Perangkat lunak (Software)

Tabel 2

Spesifikasi Perangkat lunak

\begin{tabular}{|c|l|l|}
\hline No & Jenis Software & Nama Software \\
\hline 1 & Sistem Operasi & $\begin{array}{l}\text { Microsoft } \\
\text { Windows 8 }\end{array}$ \\
\hline 2 & $\begin{array}{l}\text { Bahasa } \\
\text { Pemrograman }\end{array}$ & Visual Basic.net \\
\hline 4 & $\begin{array}{l}\text { Database } \\
\text { Server }\end{array}$ & MySQL \\
\hline 6 & Code Editor & Notepad++ \\
\hline 7 & Image Editor & $\begin{array}{l}\text { Adobe } \\
\text { Photoshop CS4 }\end{array}$ \\
\hline
\end{tabular}

\section{KESIMPULAN}

Aplikasi Kelayakan Kredit Mikro ini yang didukung oleh Bahasa pemograman Visual Basic.net yang memungkinkan proses kredit mikro mampu proses lebih cepatdan menyimpannya kedaam suatu database. Maka dapat ditarik suatu kesimpulan bahwa :

1. Dengan dibuatnya suatu aplikasi kelayakan kredit mikro, maka diharapkan peroses kredit mikro mampu lebih cepat dalam memproses.

2. Dengan adanya suatu database, mampu mempermudah pencarian file yg sudah ada, sehingga user tidak pelu memakan waktu yg banyak untuk pencarian data.

3. Dengan adanya sistem yang telah terintegrasi dapat mempermudah dalam mengetahui informasi nasabah.

Aplikasi kelayakan kredit mikro yang telah dibuat ini masih banyak kekurangan terutama dari segi keamanan dikarenakan keterbatasan kemampuan dan pengetahuan, sehingga perlu dikembangkan lagi agar aplikasi ini bisa lebih sempurna. Saran untuk aplikasi kelayakan kredit mikro ini adalah :

1. Diharapkan aplikasi ini dapat lebih dikembangkan dalam menangani sistem online, sebab aplikasi ini belum dapat digunakanonline secara aman.

2. Diharapkan aplikasi ini dapat digunakan oleh uses pengguna yang memproses kredit mikro dan menjalankannya dengan baik. 
Diharapkan adanya pengembangan dari segi keamanan sehingga aplikasi kelayakan kredit mikro ini dapat lebih berkualitas.

\section{DAFTAR PUSTAKA}

[1] Arfyanti, I., Purwanto, E., 2012. Aplikasi Sistem Pendukung Keputusan Pemberian Kelayakan Kredit Pinjaman pada Bank Rakyat Indonesia Unit Segiri Samarinda Dengan Metoda Fuzzy MADM (Multiple Attribute Decission Making) Menggunakan SAW (Simple Additive Weighting), Prosiding Seminar Nasional Teknologi dan Komunikasi Terpan (Semantik 2012), Semarang.
[2] Pressman, R. S., 2002. Rekayasa Perangkat Lunak Pendekatan Praktisi (Buku. Satu), ANDI Yogyakarta.

[3] Hendrawan, W., 2009. Software System Requirement Management Planning, Artikel, BINUS University. http://weha88.blog.binusian.org/files/ 2009/06/gabungan-paper-2.doc, diakses September 2016 